\title{
Identificação do circovírus suíno tipo 2 por reação em cadeia da polimerase e por imunoistoquímica em tecidos suínos arquivados desde 1988 no Brasil
}

\author{
Identification of porcine circovirus type 2 by polymerase chain reaction and \\ immunohistochemistry on archived porcine tissues since 1988 in Brazil
}

\author{
Janice Reis Ciacci-Zanella ${ }^{1}$ Nelson Morés ${ }^{2}$ Neide Lisiane Simon ${ }^{1}$ \\ Salete Rodrigues de Oliveira ${ }^{2}$ Danielle Gava ${ }^{3}$
}

\section{RESUMO}

A síndrome multissistêmica do definhamento dos suínos (SMDS) é uma doença de importância econômica causada pelo circovírus suíno tipo 2 (PCV2). Uma pesquisa retrospectiva foi realizada em amostras de órgãos de suínos fixados em blocos de parafina arquivados, que haviam sido submetidos à Embrapa Suínos e Aves entre 1985 e 1998 para o diagnóstico histopatológico. Vinte e cinco casos foram selecionados com base nas lesões histológicas características da SMDS, tais como linfoadenopatia, pneumonia intersticial, hepatite e nefrite intersticial. A presença de PCV2 nos cortes histológicos foi pesquisada por reação em cadeia da polimerase interna (nested-PCR), na qual utilizou-se primers específicos para a seqüência da ORF2 do PCV2 e também por imunoistoquímica, utilizando um anticorpo monoclonal específico para o capsídeo do PCV2. O DNA viral e os antígenos específicos do PCV2 foram detectados em amostras de tecidos de dois dos 25 casos analisados, sendo um desses datado de 1988. Esses resultados indicam que o PCV2 já estava presente no Brasil desde 1988.

Palavras-chave: circovírus suíno tipo 2 (PCV2), síndrome multissistêmica do definhamento (SMDS), estudo retrospectivo, síndrome da dermatite e nefropatia (SDNS).

\section{ABSTRACT}

Postweaning multisystemic wasting syndrome (PMWS) is of economical importance a disease caused by porcine circovirus type 2 (PCV2). A retrospective investigation was performed on paraffin-embedded organs samples from swine submitted to Embrapa Swine and Poultry Research Center between 1985 and 1998 for histopathologic diagnosis. A total of 25 cases were chosen from the archival collection of the Animal Health Laboratory at Embrapa Swine and Poultry based on characteristic pathological lesions of PMWS, such as lymphadenopathy, interstitial pneumonia, hepatitis and interstitial nephritis. The sections were investigated by nestedPCR (polymerase chain reaction) which used specific primers for the ORF2 sequence of the PCV2 and by immunohistochemistry using a monoclonal antibody specific for PCV2 capsid antigen. Virus specific DNA and antigen were detected in tissue samples of two out of 25 analyzed cases. The earliest positive sample originated from 1988. These results indicate that PCV2 is present in Brazil since 1988.

Key words: porcine circovirus type 2 (PCV2), post weaning multisystemic wasting syndrome (PMWS), retrospective, porcine dermatitis and nephropathy syndrome (PDNS).

\section{INTRODUÇÃO}

A circovirose suína é uma infecção viral de grande importância econômica, com distribuição mundial e causada pelo circovírus suíno tipo 2 (PCV2) (ALLAN et al., 1998, ALLAN \& ELLIS, 2000). A circovirose suína pode se manifestar de diversas formas, porém as mais freqüentes são a síndrome multissistêmica do definhamento dos suínos (SMDS) e a síndrome da dermatite e nefropatia suína (SDNS) (ALLAN \& ELLIS, 2000).

O circovírus suíno (PCV) foi identificado em 1974 como contaminante de linhagens contínuas de células renais de suínos (PK15) (TISCHER et al., 1974). São conhecidos dois tipos de PCV: o circovírus suíno tipo 1 (PCV1), contaminante de células PK15, apatogênico para suínos, e o circovírus suíno tipo 2

\footnotetext{
${ }^{1}$ Laboratório de Virologia, Embrapa Suínos e Aves, 89700-000, Concórdia, SC, Brasil. E-mail: Janice@cnpsa.embrapa.br. Autor para correspondência.

${ }^{2}$ Laboratório de Patologia, Embrapa Suínos e Aves, Concórdia, SC, Brasil.

${ }^{3}$ Centro de Ciências Agroveterinárias (CAV), Universidade do Estado de Santa Catarina (UDESC), Lages, SC, Brasil.
} 
(PCV2), associado a SMDS e SDNS. Os circovírus suínos são vírus pequenos, com 17nm de diâmetro, icosaédricos, não-envelopados e possuem um dos menores genomas entre os vírus que infectam vertebrados, com aproximadamente 1.760 nucleotídeos (TODD, 2000).

A SMDS é uma doença emergente causada pelo PCV2, que causa elevada mortalidade em suínos nas fases de creche e de crescimento - terminação (ALLAN et al., 1998). Clinicamente, é caracterizada por emagrecimento progressivo, dispnéia, anemia, aumento do volume dos linfonodos superficiais inguinais, diarréia, icterícia e morte (CLARK, 1997; ROSELL et al., 1999). As lesões histopatológicas atribuídas à SMDS são observadas em diversos órgãos, mas predominantemente nos órgãos linfóides. Essas lesões consistem em depleção linfocitária com presença de corpúsculos de inclusão intracitoplasmáticos, que são encontrados nas áreas dos linfonodos dependentes de célula $B$, podendo ocorrer em células dispersas neste órgão. Essas células são geralmente da linhagem monocítica (macrófagos e células dendríticas). Também se observam lesões com ocorrência e freqüência variável como hepatites, nefrites e pneumonia intersticial nos animais infectados (ELLIS et al., 1998; ROSELL et al., 1999). Na SDNS, há predominância de lesões de pele e renais (ELLIS et al., 1998; ROSELL et al., 1999).

A enfermidade foi reconhecida pela primeira vez no Canadá, em 1991, e, desde então, tem sido descrita em vários países (CLARK, 1997; ALLAN \& ELLIS, 2000). No Brasil, o PCV2 associado à SMDS foi diagnosticado pela primeira vez em 2000 (ZANELLA \& MORES, 2000; CIACCI-ZANELLA \& MORES, 2003), e, atualmente, acredita-se que a infecção esteja disseminada no rebanho suíno brasileiro (BARBOSA, 2005). Existem relatos recentes de estudos retrospectivos sobre a identificação da doença: desde 1986, na Espanha (RODRIGUEZ-ARRIOJA et al., 2003), na Inglaterra (SANDVIK et al., 2001) e na Suíça (STAEBLER et al., 2005); desde 1989, no Japão (MORI et al., 2000); e, desde 1993, na Tailândia (KIATPATTANASAKUL-BANLUNARA et al., 2002). Em especial, estudos retrospectivos para detecção de anticorpos para PCV1 e PCV2 em amostras de soros suíno coletadas em abatedouros no Canadá, em 1985, 1989 e 1997, indicaram que o PCV2 estava presente nestes suínos pelo menos dez anos antes da primeira identificação de SMDS (MAGAR et al., 2000). Além disso, caracterizações antigênicas e genômicas de amostras virais não indicaram diferenças significativas quando compararam PCV2 isolado de casos recentes com aqueles mais antigos presentes nos arquivos (BOLIN \&ALLAN, 2002).
Dessa forma, considera-se que a doença também possa ter ocorrido no Brasil antes da sua primeira identificação em 2000. O objetivo deste trabalho foi realizar um estudo retrospectivo em órgãos de suínos armazenados em blocos de parafina, submetidos a diagnóstico histopatológico na Embrapa Suínos e Aves (Concórdia, SC), no período entre 1985 e 1998, para identificar a presença do PCV2. Além disso, objetivou-se reavaliar se as lesões observadas nestes órgãos infectados com o PCV2 eram compatíveis com aquelas da SMDS e SDNS, visando a estudar a manifestação patogênica da infecção pelo PCV2 em suínos no Brasil.

\section{MATERIAL E MÉTODOS}

\section{Cortes histológicos}

Foram selecionados da coleção de arquivos do Laboratório de Sanidade da Embrapa Suínos e Aves (Concórdia, SC), Setor de Patologia, blocos de parafina contendo fragmentos de órgãos de suínos enviados para diagnóstico nos anos de 1985 a 1998, provenientes de granjas de suínos de diferentes regiões no Brasil. Com base no histórico clínico e lesões macro e microscópicas de linfadenopatia, pneumonia intersticial, hepatite e/ou nefrite intersticial, foram selecionados 25 casos.

\section{Detecção por nested-PCR}

A detecção de DNA de PCV2 nos órgãos dos suínos foi realizada por meio da técnica de nestedPCR, descrita por KIM et al. (2001). Cortes histológicos de $10 \mu \mathrm{m}$ dos tecidos parafinizados foram desparafinizados com xilol. Cada amostra processada continha um pool de órgãos do mesmo animal. O material foi centrifugado, lavado com etanol 100\% para remoção do solvente e o sobrenadante foi descartado. $\mathrm{O}$ tecido sedimentado foi submetido a digestão a $56^{\circ} \mathrm{C}$, por quatro horas, em tampão de lise (200mM NaCl, 100 mM Trizma Base pH 7,5, 20mM EDTA 0,5M pH 8,0 e $1 \%$ SDS) e $20 \mu \mathrm{g} / \mathrm{ml}$ de proteinase K (Sigma Chemical, St. Louis, EUA). O DNA foi extraído com fenol: clorofórmio: álcool isoamílico (25:24:1), precipitado com $10 \mathrm{M}$ de acetato de sódio (0,3 volumes) e etanol absoluto (dois volumes), o qual foi mantido por 20 horas a $20^{\circ} \mathrm{C}$. O DNA foi lavado em etanol 75\%, que foi centrifugado a $5.000 \mathrm{~g}$ por cinco minutos, tendo-se retirado o sobrenadante e o pellet ressuspenso em $100 \mu \mathrm{l}$ de tampão TE (10mM Trizma Base pH 7,5 e 1mM EDTA0,5 $\mathrm{M} \mathrm{pH} \mathrm{8,0),} \mathrm{conforme} \mathrm{SAMBROOK} \mathrm{et} \mathrm{al.} \mathrm{(1989).} \mathrm{Para}$ realização da nested-PCR, primers aneladores 
específicos para a ORF2 (fase aberta de leitura 2) do PCV2, que é altamente conservada entre os vários isolados do vírus, foram utilizados e a reação foi realizada conforme escrito por KIM et al. (2001). Como controle positivo, foi utilizada a amostra de PCV2 isolada de suínos com sinais clínicos e lesões de circovirose suína (CIACCI-ZANELLA \& MORES, 2003). Água ultrapura foi utilizada como controle negativo das reações. Os materiais positivos na técnica de nested-PCR foram submetidos ao exame histopatológico e de imunoistoquímica.

\section{Imunoistoquímica}

Amostras de tecidos de suínos com lesões microscópicas sugestivas de circovirose e positivos para PCV-2 pela técnica de reação da polimerase em cadeia interna (nested-PCR) foram seccionadas em $4 \mu \mathrm{m}$ e colocadas sobre lâminas de vidros revestidas com poly-L-lisina para coloração de imunoperoxidase. Como controle negativo, foram utilizados cortes de linfonodos de animais livres de patógenos específicos (SPF). Como controle positivo, foram utilizados cortes de linfonodos de suínos com lesões sugestivas de SMDS e com diagnóstico confirmado por nested-PCR. Os cortes foram desparafinados em xilol e reidratados em soluções em álcool decrescentes. A recuperação antigênica foi realizada com tripsina 1\% durante 10 minutos. Em seguida, procedeu-se o bloqueio da peroxidase endógena com $\mathrm{H}_{2} \mathrm{O}_{2} 3 \%$. $\mathrm{O}$ anticorpo monoclonal (9H7) contra a proteína codificada pela ORF2 (capsídeo) do PCV2 (gentimente cedido por Fernando Osório, Universidade de Nebraska, Estados Unidos) foi testado anteriormente e reconheceu epitopos conformacionais da proteína do capsídeo do PCV2, não reagindo com o PCV1 e com células de cultivo laboratorial não-infectadas com PCV2. O anticorpo monoclonal foi adicionado na diluição de 1:200, incubando os tecidos a temperatura de $37^{\circ} \mathrm{C}$, durante uma hora e meia. Para coloração dos tecidos, utilizou-se o ExtrAvidin Peroxidase Staining Kit ${ }^{\circledR}$ (Sigma E-8386). O anticorpo secundário biotinilado foi usado na diluição 1:15 por 30 minutos à $37^{\circ} \mathrm{C}$. Logo após isso, os cortes foram incubados a $37^{\circ} \mathrm{C}$, por meia hora, com o conjugado extravidina-peroxidase na diluição 1:15. Por fim, a revelação da reação foi feita com 3-amino-9dietilcarbazol (AEC), por 5 minutos, em temperatura ambiente. As lâminas foram contracoradas com hematoxilina de Mayer por dois minutos e examinadas em microscópio ótico. Em cada bateria de teste, foram utilizadas lâminas contendo os controles positivo e negativo para PCV-2 em duplicata, sendo uma lâmina incubada com o anticorpo primário e outra (duplicata) incubada com TBS pH 7,6 (Tris buffered saline, 10mM Tris-HCl; 150mM NaCl). Como solução de lavagem das lâminas entre cada passo, foi utilizado TBS com 0,05\% de Tween 20. Todas as incubações foram realizadas em câmara úmida a $37^{\circ} \mathrm{C}$.

\section{RESULTADOS E DISCUSSÃO}

Das 25 amostras de órgãos selecionadas, duas resultaram positivas na reação de nested-PCR, que resultou na amplificação de um produto esperado de 225 pares de base (pb) específico para a região da ORF2 do PCV2 (Figura 1). As amostras positivas correspondem aos protocolos dos anos 1988 (Prot. 826/ 88), diagnosticado inicialmente como hepatite (Figura 2), e 1990 (Prot. 78/90), diagnosticado inicialmente como glomerulonefrite (Figura 3). Esses resultados indicam que o PCV2 já estava presente em plantéis de suínos no Brasil desde 1988. O material estudado estava armazenado por longo tempo no laboratório antes da realização destas análises. Isso pode ter comprometido a viabilidade de antígenos e de DNA do PCV2 e, talvez por isso, apenas 2 dos 25 casos selecionados forem positivos, o que é um problema freqüente neste tipo de estudo retrospectivo.

Para o diagnóstico da circovirose suína, é importante a associação dos sinais clínicos com os achados macro e microscópicos e com a identificação do agente (SEGALÉS, 2002). Análises histopatológicas das lâminas dos materiais positivos por nested-PCR indicam que o material do protocolo 826/88 apresenta lesões no fígado de infiltração linfoplasmocitária na região portal (Figura 2), células de Küpffer demonstrando hiperatividade e fibrosamento da cápsula de Glisson, com leve infiltração linfoplasmocitária. Análises do material do protocolo 78/90 indicam glomerulonefrite mononuclear severa e difusa (Figura 3); glomérulos diminuídos de tamanho com fibrose da cápsula de Bowman e do tufo glomerular; dilatação do espaço de Bowman por material amorfo em início de organização por fibrose; túbulos renais dilatados, contendo material amorfo hialino e epitélio achatado; alguns túbulos renais com degeneração granular hialina do citoplasma das células epiteliais; difusa infiltração linfoplasmocitária e de alguns eosinófilos no interstício, tanto na camada medular como na cortical. Essas lesões são compatíveis com a manifestação patológica da SDNS. Não foi observada a presença de corpúsculo de inclusão no material submetido ao exame histopatológico.

Uma outra evidência da presença do PCV2 foi encontrada por meio da detecção de antígeno de 


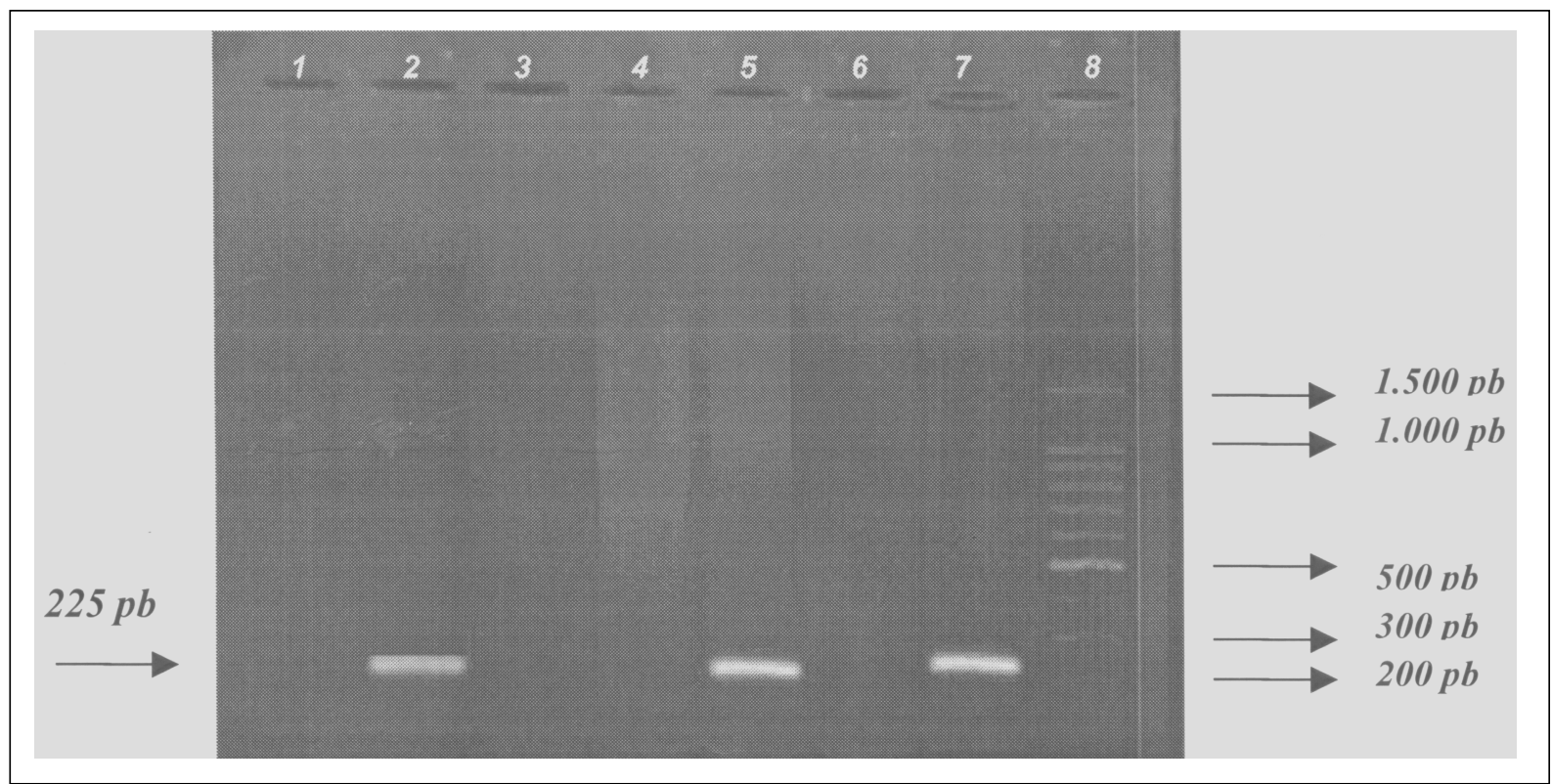

Figura 1 - Gel de agarose indicando os resultados dos testes de nested-PCR em DNA extraído de órgãos suínos dos protocolos dos anos 1988 e 1990. A reação resultou num produto amplificado de 225 pares de base (pb) específico para a região da ORF2 do PCV2. A linha 1 corresponde à reação de amplificação de DNA do protocolo 892/88 (-), a linha 2 ao prot. 826/88 (+), a linha 3 ao prot. 463/88 (-), a linha 4 ao prot. 187/90 (-), a linha 5 ao prot. 78/90 (+), a linha 6 ao controle negativo (água estéril), a linha 7 ao controle positivo (CIACCI-ZANELLA \& MORES, 2003), e a linha 8 ao marcador de peso molecular de 100 pb (Promega, Madison, WI, EUA).

PCV2 por imunoistoquímica. Cortes de rins do suíno do protocolo 78/90, conforme apresentado na figura 4, demonstraram a presença de escassa quantidade de antígeno nos infiltrados inflamatórios, principalmente em macrófagos, e também no citoplasma de células dos túbulos renais imaturos, mesclada com o material presente no interior dos túbulos. Como o material analisado neste estudo eram blocos de parafina da coleção de arquivos do Laboratório de Patologia, não foi possível avaliar os tecidos linfóides dos suínos positivos por nested-PCR, pois estes órgãos já haviam sido descartados. As lesões características de SMDS nestes órgãos são importantes para o diagnóstico definitivo da SMDS (SEGALÉS, 2002). Porém, vale ressaltar que, das amostras disponíveis para exame, tanto o fígado como os rins apresentaram lesões microscópicas compatíveis com a circovirose suína ou SDNS, ambos os órgãos continham DNA e antígeno de PCV2 (este último detectado somente no rim).

Esses resultados demonstram que a circovirose suína está presente no Brasil desde 1988, apesar de o PCV2 como agente portal do fígado, lesão característica de hepatite com infiltrado mononuclear. Magnificação 420x. 


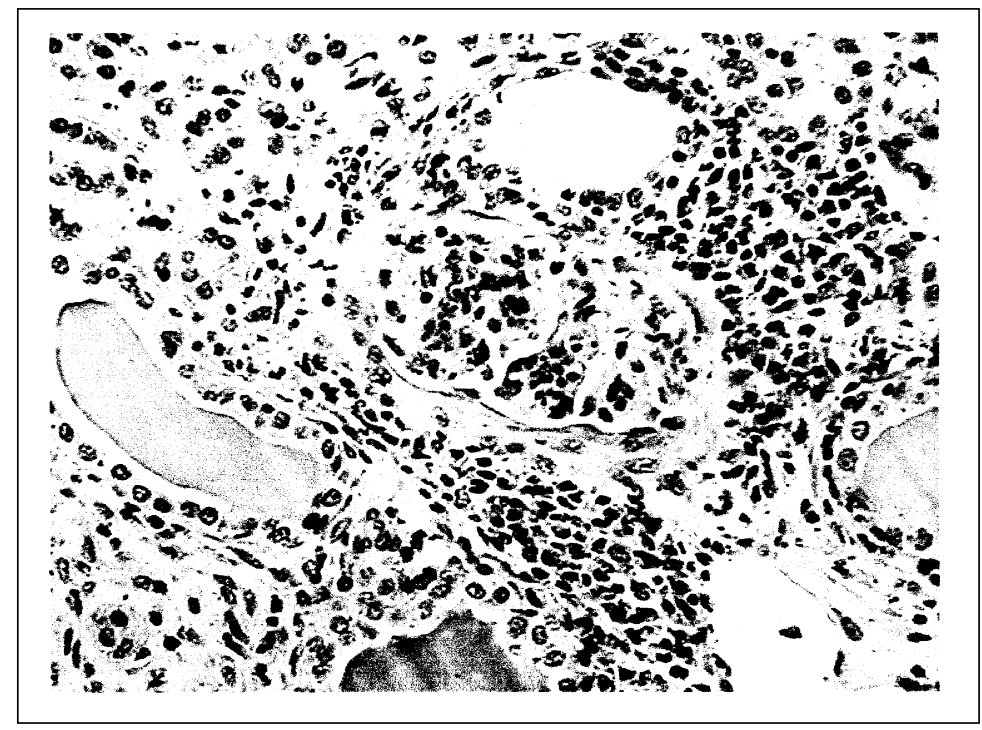

Figura 3 - Rim, protocolo 78/90. Coloração de hematoxilina e eosina, glomerulonefrite com infiltrado linfohistiocitário, dilatação tubular e presença de material hialino no interior dos túbulos renais. Magnificação 420x. repentinamente, tornou-se uma doença de grande importância econômica para a suinocultura mundial, desde que se reproduziu os sinais clínicos da doença e replicação viral doença em 1997 no Canadá (CLARK, 1997; ALLAN et al., 1999). Num ponto de vista evolutivo entre vírus e hospedeiro, suspeita-se que a circovirose seja um desbalanço na relação vírus-hospedeiro (VISSCHER et al., 2002). Estudos retrospectivos realizados em outros países não apontaram diferenças genéticas e antigênicas das amostras de PCV2 isoladas de casos recentes de SDMS com aquelas amostras de arquivos, indicando que não houve mudanças significativas na virulência do PCV2 (BOLIN \& ALLAN, 2002). Desta forma, suspeita-se que a emergência da circovirose suína tenha ocorrido como conseqüência das mudanças nas práticas de manejo, na genética do hospedeiro ou da emergência de outros agentes que aumentam a gravidade da doença decorrente também de infecções mistas (STAEBLER et al., 2005). Análises genômicas comparativas das amostras de PCV2 descritas neste estudo estão em andamento.

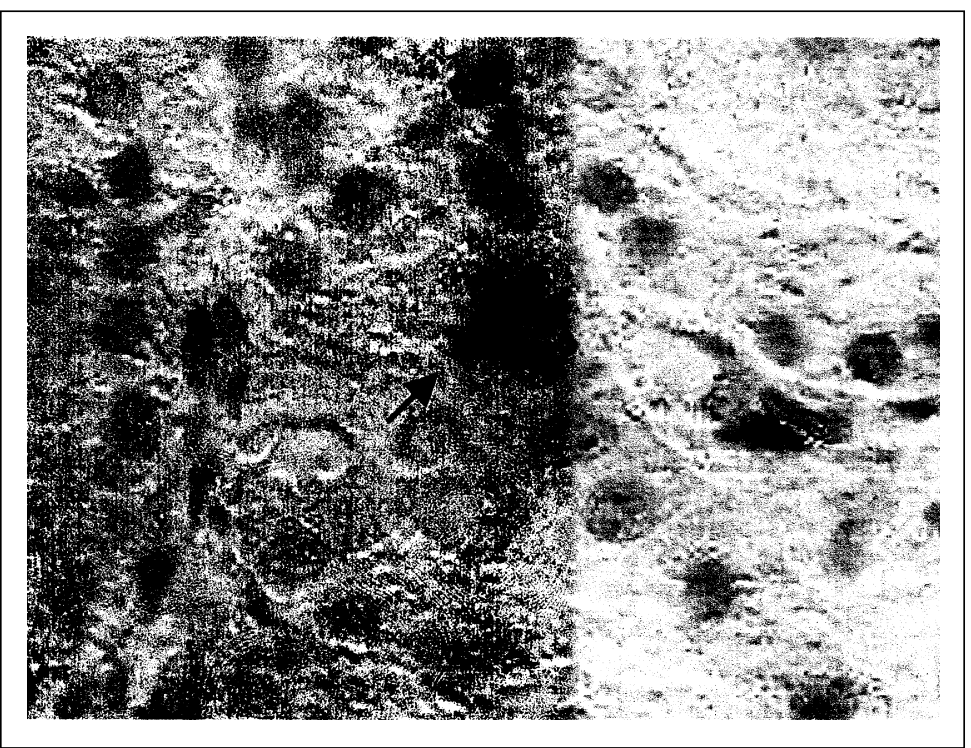

Figura 4 - Rim, protocolo 78/90. Reação de imunoistoquímica, citoplasma de células de túbulos renais marcadas para a presença do antígeno (seta). Magnificação 640x.

\section{CONCLUSÃO}

A circovirose suína foi diagnosticada em órgãos parafinizados datados de 1988, os quais se encontravam no arquivo do laboratório de Sanidade da Embrapa Suínos e Aves, por meio da amplificação doDNAdoPCV2pornestedPCR, da identificação de lesões histopatológicas e da demonstração de antígeno de PCV2 nos tecidos, indicando que a infecção já estava presente no Brasil desde aquela época.

\section{AGRADECIMENTOS}

Este trabalho foi realizado devido ao suporte de projetos financiados pela EMBRAPA e pelo CNPq. Danielle Gava é estudante de mestrado e bolsista da Coordenação de Aperfeiçoamento de Pessoal de Nível Superior (CAPES). 


\section{REFERÊNCIAS}

ALLAN, G.M. et al. Isolation of porcine circovirus-like viruses from pigs with a wasting disease in the USA and Europe. J Vet Diagn Investig, v.10, p.3-10, 1998.

ALLAN, G.M. et al. Experimental reproduction of severe wasting disease by co-infection of pigs with porcine circovirus and porcine parvovirus. J Comp Pathol, v.121, p.1-11, 1999.

ALLAN, G.M.; ELLIS, J. Porcine circovirus: a review. J Vet Diagn Investig, v.12, p.3-14, 2000.

BARBOSA, C.N. et. al. Estudo do perfil sorológico para o circovírus síno tipo 2 (CVS-2) em granjas tecnificadas para produção comercial de suínos. In: ABRAVES, 12., 2005 , Fortaleza, CE. Anais... Fortaleza, CE: ABRAVES, 2005. V.II, p.97-98.

BOLIN, S.R.; ALLAN, G.M. Old virus or new virus - In a world of continuous changes. PMWS and PCV2 diseases beyond the debate. In: INTERNATIONAL PIG VETERINARY SOCIETY CONGRESS, 17., 2002, Ames. Proceedings... Ames, EUA: IPVS, 2002. p.9-17.

CLARK, E.G. Post weaning multisystemic wasting syndrome. Proc Am Assoc Swine Pract, v.28, p.499-501, 1997.

CIACCI-ZANELLA, J.R.; MORES, N. Diagnostic of postweaning multisystemic wasting syndrome (PMWS) in swine in Brazil caused by porcine circovirus type 2 (PCV2). Arq Bras Med Vet Zoot v.55, p.522-527, 2003.

ELLIS, J. et al. Isolation of circovirus from lesions of pigs with postweaning multisystemic wasting syndrome. Can Vet J, v.39, p.44-51, 1998.

KIATPATTANASAKUL-BANLUNARA, W. et al. Detection of porcine circovirus type 2 (PCV2) DNA by nested PCR from formalin fixed tissues of postweaning multisystemic wasting syndrome (PMWS) pigs in Thailand. J Vet Med Sci, v.64, p.449-452, 2002

KIM, J. et al. Differentiation of porcine circovirus PCV1 and PCV2 in boar semen using a multiplex nested polymerase chain reaction. J Virol Met, v.98, n.1, p.25-31, 2001.

MAGAR, R. et. al. Retrospective serological survey of antibodies to porcine circovirus type 1 and type 2. Can J Vet Res, v.64, n.3, p.184-186, 2000.
MORI, M. et al. Retrospective study of porcine circovirus 2 infection in Japan: seven cases in 1989. Vet Pathol, v.37, p.667-669, 2000.

RODRIGUEZ-ARRIOJA, G.M. et al. Retrospective study on porcine circovirus type 2 infection in pigs from 1985 to 1997 in Spain. J Vet Med, v.50, p.99-101, 2003.

ROSELL, C. et al. Pathological, immunohistochemical, and in situ hybridization studies of natural cases of post-weaning multisystemic wasting syndrome (PMWS) in pigs. J Comp Pathol, v.120, p.59-68, 1999.

SAMBROOK, J. et al. Molecular cloning, a laboratory manual. 2.ed. New York: Cold Spring Harbor Laboratory, 1989. V.3, 545p.

SANDVIK, T. et al. Detection and genetic typing of porcine circovirus DNA isolated from archived parafin embedded pig tissues. In: Comparative Virology. In: ssDNA VIRUSES OF PLANTS, BIRDS, PIGS AND PRIMATES, 1., 2001, Saint Malo. Proceedings... Saint Malo, France, AFSSA, 2001. p111.

SEGALÉS, J. Update on post-weaning multisystemic wasting syndrome and porcine dermatitis and nephropathy syndrome diagnostics. J Swine Health Prod, v.10, p.277-281, 2002.

STAEBLER, S. et al. PMWS: an emerging disease identified in archived porcine tissues. Vet J, v.170, n.1, p.132-134, 2005.

TISCHER, I. et al. Characterization of papovavirus and picornavirus like particles in permanent pig kidney cell lines. Zentralbl Bakterio. Parasitenkd Infektionskr Hyg Abt 1 Orig, v.26, p.153-167, 1974.

TODD, D. Circoviruses: immunosuppressive threats to avian species: a review. Avian Pathol, v.29, p.373-394, 2000.

VISSCHER, A.H. et al. Disease incidence and immunological traits for selection of healthy pigs. Vet Quarterly, v.24, p.29-34, 2002.

ZANELLA, J.R.C.; MORES, N. Síndrome multissistêmica do definhamento do leitão desmamado (SMDLD) causada por circovírus suíno. In: CONGRESO MERCOSUR DE PRODUCCIÓN PORCINA, 2000, Buenos Aires. Memoria... Buenos Aires: Universidad de Buenos Aires, 2000. P.EIP16. 